$\S=-1$

\title{
SMART2L: Smart Water Level and Leakage Detection
}

\author{
Haikal Hafiz Kadar ${ }^{1}$, Sera Syarmila Sameon ${ }^{2}$, Mohd. Ezanee Rusli ${ }^{3}$ \\ ${ }^{1,2,3}$ College of Computer Science and Information Technology, Universiti Tenaga Nasional,Malaysia, \\ *Corresponding author E-mail: hydrogen.uranium235@gmail.com
}

\begin{abstract}
The Internet of Things (IoT) technology can assist in the effective conservation of resources and energy management. With IoT, managing water level and detecting leakage within water pipeline distribution system can be automated. This is the golden opportunity as the field of water management and distribution progress with the advancement of IoT. Water shortage has been part of the crucial complications that encountered by many municipalities around the globe and surplus during transmission has been acknowledged as the main problem. Thus, the key idea for this project is to design a real-time low cost wireless system called as SMART2L to prevent Non-Revenue Water (NRW) commonly known as unbilled water wastage. SMART2L integrates with Internet of Things (IoT) that will make a change to the way of people live and manage their water resources smartly.
\end{abstract}

Keywords: Internet of Things (IoT), Leakage, Water Level, Water Pump, Mobile Apps, Notification, E-tape, Flowrate, Wi-Fi, Firebase.

\section{Introduction}

With the advancement of IoT and sensors, liquid level and leakage sensing will be the big part of an operational IoT-based applications. For an example, a smart device developed by Ravichandran in 2016 to estimate accurately the liquid level and to prevent an overflow and to detect leakage. Basically, the smart device provides a solution to measure the quantity and liquid level in a liquid transmission system using sensor based wireless technology [1]. Besides that, IoT technology allows device-todevice communication that permit exchange of messages to attain those functionalities [2]. These devices or sensors can communicate to almost many type of networks and this includes the Internet. With the help of IoT, the capability to code and track objects has permitted companies to become more well-organized, promptness in their processes, diminish errors, avert theft, and uniting complex and flexible organizational systems through IoT [3]. The IoT is a technological revolution that represents the future of computing and communications, and its development depends on dynamic technical innovation in a number of important fields, from wireless sensors to nanotechnology. In principle, each object can be tagged for identifying, automating, monitoring and controlling [3].

Water is an essential resource and the most important element needed by humans. Due to global environmental situation, water management and conservation is vital for human survival. In addition, water is also used in various places such as industries, domestic, and power plants [4], [5]. Burst pipe, overflow of water from tank and a water leakage is another major reason for wastage of water [5]. In recent times, there were huge needs of detecting and monitoring water level and leakage that could be swiftly established using Internet of Things (IoT) technology [6]. Therefore, efficient use and water monitoring are potential constraint for offices, institutions and industries water management system.

Internet of Things (IoT) enables us to build a system without human interference [5]. In other words, IoT is an environment that has the ability to transfer data over a network without human to human or human to computer interaction [5]. The IoT also allows objects to be sensed and controlled remotely across existing network infrastructure, creating opportunities for direct integration between the physical world and computer based [5]. Thus, it provides more efficiency, accuracy as well as economic benefits. In this paper, SMART2L system is proposed that uses the Wi-Fi to establish direct sensor-to-sensor communication. The technique of sensing the tank water level and monitoring leakage are integrated with some basic parts in our proposed method.

\section{Related Issues of Non-Revenue Water (NRW)}

Non-revenue water (NRW) can best be defined as the difference between the volume of water put into a water distribution system and the volume that is billed to customers. NRW is currently being one of the concerns intensely conversed internationally. Unquestionably, there are many approaches to monitor both water and leakages but this issue still rises over the years. Currently, the average NRW level documented nationwide for Malaysia is $35.5 \%$ [7]. In addition, leakage is the main caused for as much as $70 \%$ of Malaysia's average NRW [7]. From the observations, many states recorded a high NRW level exceeding the Malaysia's average NRW like Kelantan ( $49 \%$ and increasing due to more AC pipes usage), Kedah (46.7 and increases up to 53.9\%), Perlis (highest with 56.3\%) Pahang (52.8\%), Sabah (55.1\%) [8].

In December 2014, the water crisis had disrupted and distressed the consumers in Malaysia. The reasons to such water scarcity disaster was deduced due to leakage pipelines, broken channel and rust. Therefore, there is an urgency to detect the leakage of water in overall system due to high cost of Non-Revenue Water (NRW). Knowing the volume of water in a particular tank can be a tedious work. Frequently, operators will end up climbing up and down the stairs to check on the water level parameter, manually. Most offered water level system integrated the dipped electrodes or float switches, which in return gives nuisance in the long run. Water leakage can be part of the common problem in water distribution 
system, especially when monitoring the water level. Negative outputs include wastage of billions of ringgits as well as creating hazards to public health. Cost can be associated with unbilled distributed water whereby leakage is the main contributor of this problem. On top of that, negligence of operators serve additional problem too. Operators fail to follow the standard SOP procedures or protocols. Therefore, sophisticated and well-defined water management system is required.

Thus far, these are the reasons to have a better, accurate and precise water level and leakage monitoring system. It is for these reasons that performance-based system, where performance and improvement are made against clear objectives in addressing the mentioned concerns with immediate financial and operational advantages. It can therefore create a positive dynamic and momentum to give the institutional and governance a push that effectively serve the needs of the increasing population especially in developing countries.

\section{The Proposed System}

The main purpose of SMART2L system is to aid users to monitor and manage the water level and leakage within a water distribution system. In this system, few sensors will be integrated to guarantee the security and efficiency of the process that serve to design a small-scale automated liquid using Arduino, to monitor water level and detect any leakage within the system, and calculate the flowrate and volume of water output via mobile apps. Besides that, it is aimed to avoid tank from drying or overflow during the process, reducing manpower and power consumption and most importantly, to alert the users using e-mail notification system.

The SMART2L integrates e-tape water level sensor to determine the position of the surface inside the tank and leakage sensor to detect any leaks, ruptures or small seeps. These sensors will detect any changes within the system and SMART2L will send e-mail to notify the user and automatically control the pump. The flowrate sensor is also used to calculate the flowrate of the water and the volume of water output. Figure 1 highlights the flowchart of the steps taken in implementing SMART2L system.
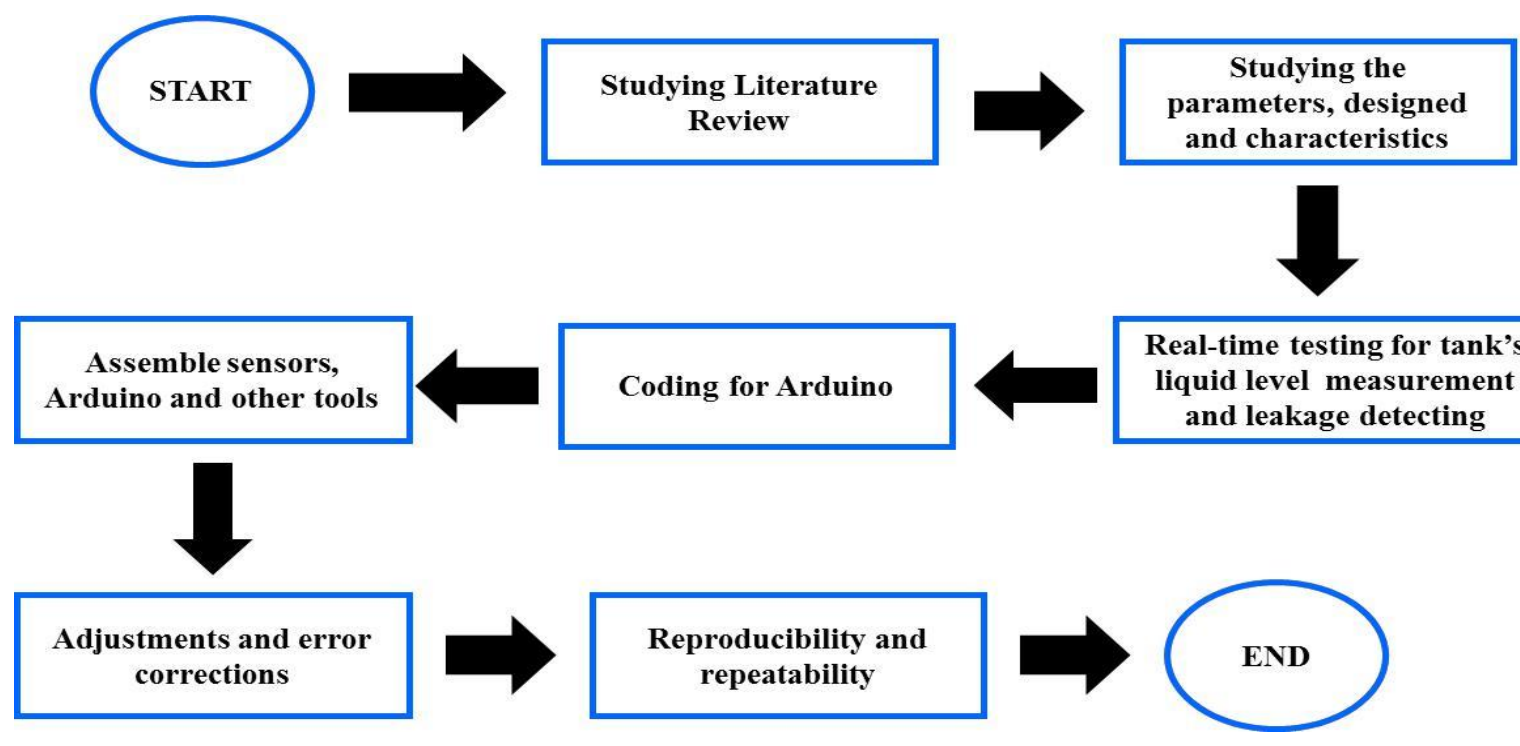

Figure 1. Overview of SMART2L Implementation Phases

The prototype of SMART2L system is designed for liquid control and leakage detection that has sensors, valves and pumps. In general, the SMART2L includes software and hardware with automation feature.

\section{Design and Implementation}

The prototype of SMART2L system uses Arduino Yun as the main controller. In addition, water pump is also used for the water pump system that consists of two type of water tanks namely; main and reserve tanks. In principle, the reserve tank is connected to the main tank through the water pump. The water pump is used to transfer water from reserve to the main tank and its operational condition (i.e. on/off) is set by the main tank's water threshold. This is the most common method for main tank which will simply start the water pump when the water level reaches its low level and will continue to pump water until the main tank is filled up. Figure 2 shows all components that are needed to develop the prototype system while Figure 3 shows the complete system of SMART2L. The sensors are all connected to the main board (Arduino Yun).

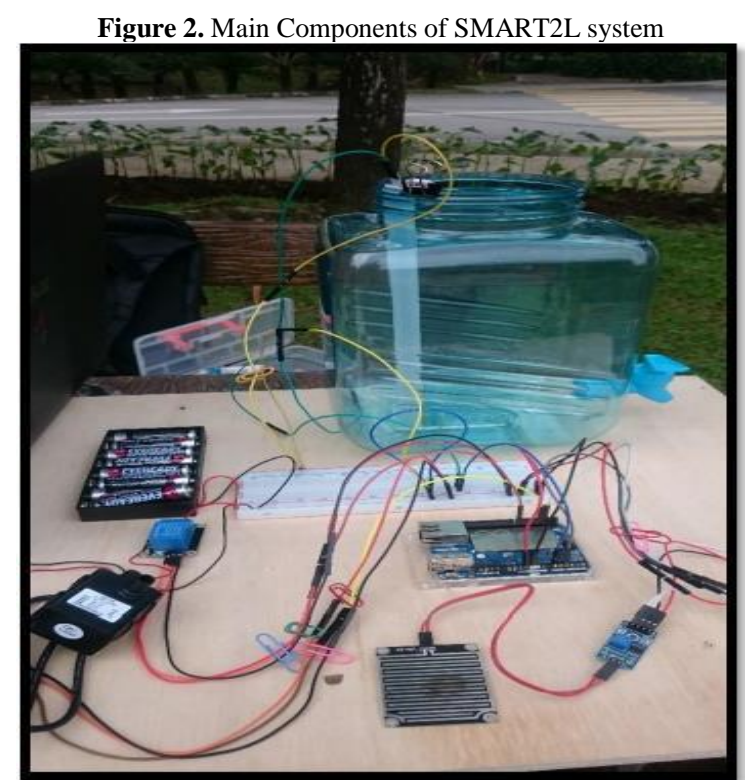

Figure 3. Sensors connected to Arduino Yun 
Basically, a small-scale pipeline system was built to test the leakage detection feature of SMART2L. In SMART2L, eTape sensor is used to monitor water level in the water tank. Moreover, different type of sensors such as liquid sensor and flowrate sensor are used to detect the presence of water at joints and to calculate the flowrate of water and volume of water output respectively. Valve is introduced to

simulate a "leakage" point on the pipeline. The basic function of SMART2L to monitor two basic conditions that may occur in the network of water pipe which are, leakage presence and leakage absence. In the event of leakage is detected, SMART2L should be able to notify the owner or operator about the situation remotely. The flowchart of the operation of SMART2L is shown in Figure 4 whereas the interface of SMART2L on android mobile devices can be seen in Figure 5.

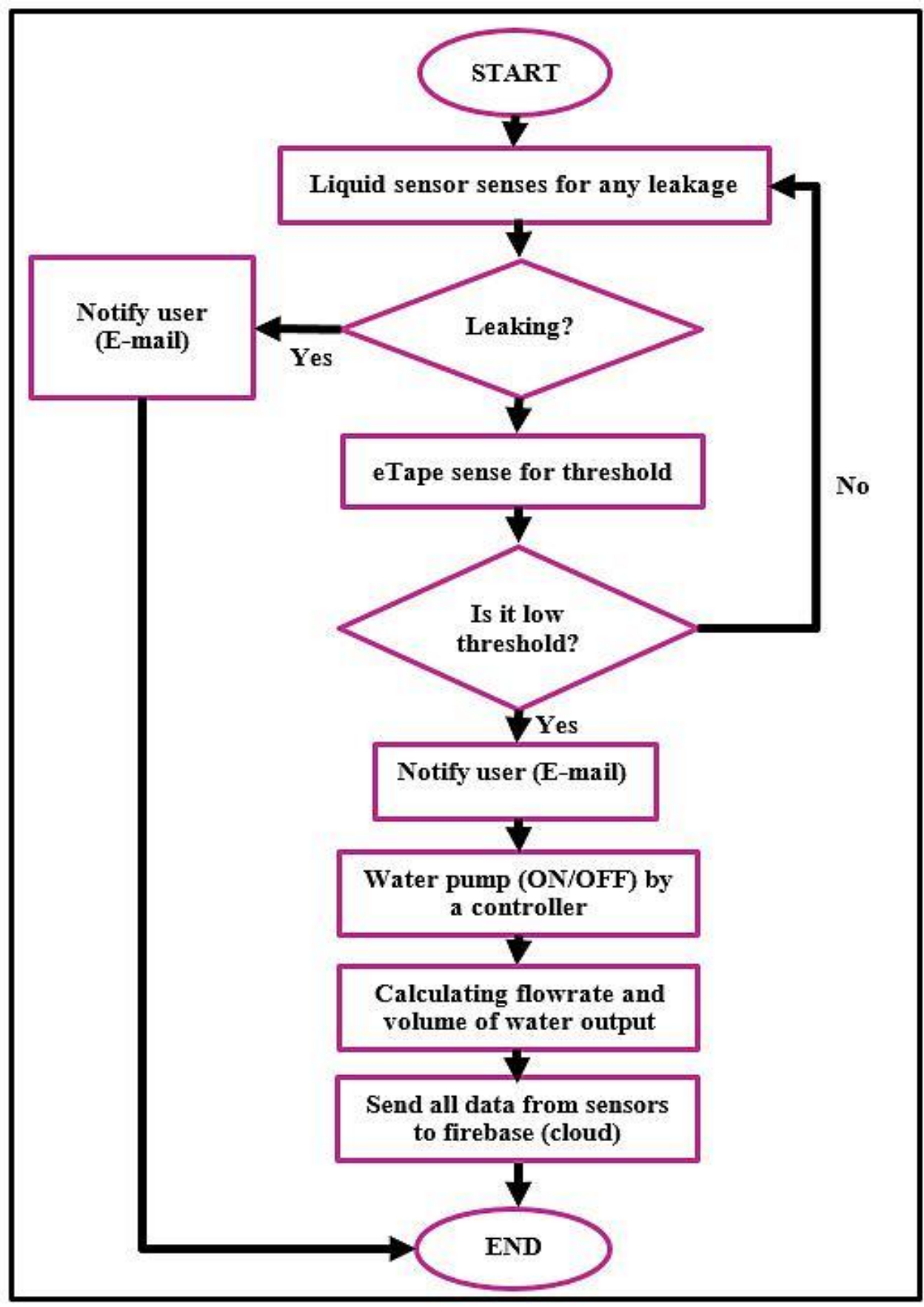

Figure 4. Flowchart of SMART2L 


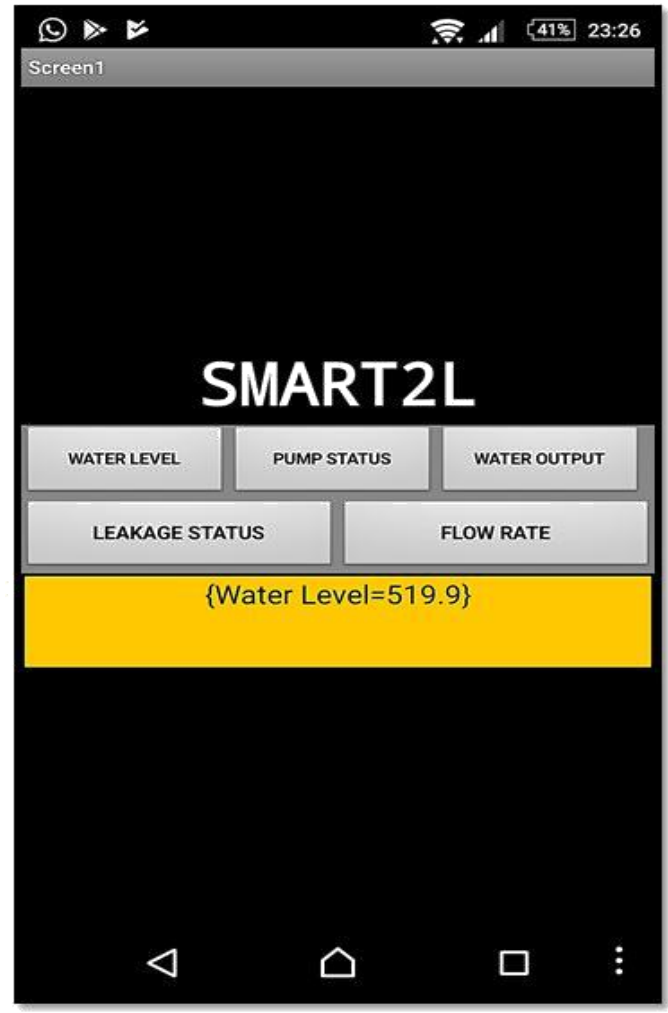

Figure 5. The interface of mobile SMART2L application

\subsection{Leakage Presence}

The liquid sensor will first detect any leakage that is present, either at the valve or along the distribution PVC pipes. If leakage is detected, the Arduino Yun will send an e-mail to notify the users. The decrease of water level below the threshold level will also cause Arduino Yun to send an e-mail too. At the same time, the water pump will be automatically activated to pump the water from the reserve tank to main tank until it full. The SMART2L mobile application need to be installed on users' smartphone to allow them to monitor SMART2L system. Whenever the leakage is detected, users will be able to directly attend to the leakage problem. This feature will save cost, time and effort in searching for the leakage within the water pipe system.

\subsection{Leakage Absence}

On the other hand, in the absence of leakage, the SMART2L system will continuously monitor the water level in the main tank. This information will be uploaded to Firebase in real time. Figure 6 shows the setting up of the testing environment for SMART2L which also highlights the email notification feature for the authorised users.

Figure 6. (a) Setting up of testing environment for SMART2L (b) E-mail notification

\section{Conclusion}

As a conclusion, the objectives of this SMART2L system are successfully achieved. This project can be implemented in real situation and can hold a market value especially in residential unit or in industries. This is because it is about time for the residential and also the industry to make a change to appreciate the benefits of IoT since they still reliably engaged to the float technology which marginally inefficient and lacking of precisions. The main reason why this project is carried out is because to reduce the high cost of Non-Revenue Water (NRW), manpower consumption and operational costs. The surplus from these reductions can be used for upgrading the maintenance of the system as maintaining water system nowadays are costly. In addition, this is to make sure that the current water distribution system we have can work along with the latest technology, Internet of Things (IoT). This warrants a well-maintained distribution system and in line with cutting-edge technology in the long run, since this project is a low-cost project that works wirelessly automatic.

Within the near future, data collection and further testing are important to study the pattern of the water level, water flow and water distribution for performance and capabilities for both the preliminary and field work. Comparisons are to be made. On top of that, the implementation can be protracted to all tanks and distribution pipes and the data collected can be utilized for data analytics such as forecasting water consumption, flow rate, output and leakage detection. This warrants a well-maintained distribution system and in line with cutting-edge technology in the long run, since this project is a low-cost project that works wirelessly automatic.

\section{References}

[1] Ravichandran, S. [2016]. Liquid Level Monitoring System Using IoT. International Science Press, IJCTA, 9(31), 215-218.

[2] Rose K., Eldrige S., \& Chapin L. [2015]. The Internet of Things: An Overview - Understand the Issues and Challenges of a More Connected World, Internet Society (ISOC).

[3] Madakam S., Ramaswamy R. \& Tripathi S. [2015]. Internet of Things (IoT): A Literature Review. Journal of Computer and Communication, 3, 164-173. Retrieved from http://dx.doi.org/10.4236/jcc.2015.35021

[4] Herlina A. R., Kharulanam A.H \& Hafilah Z. A. [2015]. Early Detection of Pipeline Using Ultrasonic Sensor. Jurnal Teknologi (Science and Engineering), 3(73), 9-11. Retrieved 28 August, 2017

[5] Arjun K,Latha C.A \& Prithviraj [2017]. Detection of Water Level, Quality and Leakage Using Raspberry Pi with Internet of Things. International Research Journal of Engineering and Technology (IRJET), 4(6), 2875-2880. Retrieved August, 2017

[6]Perumal T., Sulaiman M.N \& Leong C. Y. [2015]. Internet of Things (IoT) enabled water monitoring system. IEEE 4th Global 
Conference on COnsumer Electronics (GCCE), 86-87. doi:10.1109/GCCE.2015.7398710

[7] Tan, R. [2016]. Faulty pipes main reason for NRW, says SPAN. Selangor: The Star Online. Retrieved 29th August, 2017, from http://www.thestar.com.my/news/nation/2016/12/28/faulty-pipesmain-reason-for-nrw-says-span/

[8]Fai, \& Lee C. [2017]. Half of treated water supply in five states wasted. Selangor: The Sun Daily online. Retrieved 29th August, 2017, from http://www.thesundaily.my/news/2017/04/11/halftreated-water-supply-five-states-wasted 